\title{
Habitação social no Brasil
}

Paulo Bruna

$\mathbb{N}$ OS ÚlTIMOS anos foram publicados interessantes trabalhos sobre o problema da habitação social, ${ }^{1}$ mas nada se compara ao monumental e prodigioso conjunto de três volumes, organizado, coordenado e redigido pelo arquiteto, professor e político Nabil Bonduki. Trata-se de uma pesquisa, que é o resultado de 25 anos de estudos, inventários, levantamentos de campo e buscas em arquivos dispersos por todo o Brasil. Essa pesquisa teve, essencialmente, três fases: a primeira realizada entre 1987 e 1995, centrada no Curso de Arquitetura e Urbanismo da Escola de Engenharia de São Carlos, com a colaboração de estudantes de graduação e pós-graduação, partiu do levantamento seminal proposto pela dissertação de mestrado da professora Marta Farah (1983): Estado, Previdência Social e Habitação. Desse período resultou o primeiro trabalho importante, que foi a tese de doutorado do autor, e no livro Origens da habitação social no Brasil (Bonduki, 1994) que resgatou a produção habitacional do período 1930 a 1964. O objetivo dessa tese era identificar como o Estado acabou intervindo na questão habitacional no âmbito de um projeto de desenvolvimento urbano e industrial para o país. No dizer do autor, o foco era "revelar o contexto em que o problema habitacional transformou-se em uma questão social no Brasil" (v.l, p.3). O trabalho teve ampla repercussão nos meios acadêmicos, sobretudo porque mostrou um ciclo rico e complexo de obras realizadas pelos Institutos de Aposentadoria e Pensões (IAP) e outros órgãos atuantes naquele período.
Para aprofundar esse interesse foi proposta a segunda fase da pesquisa, entre 1997 e 2001; um projeto temático - "Habitação econômica e arquitetura moderna no Brasil", desenvolvido sob a coordenação do autor e da professora Maria Ruth Amaral de Sampaio da Faculdade de Arquitetura e Urbanismo da USP. Nessa etapa, novamente envolvendo um grande número de estudantes de iniciação científica e pós-graduação, foi realizado um extenso levantamento dos conjuntos habitacionais realizados pelos Institutos de Aposentadoria e Pensão, sobretudo nos estados de São Paulo e Rio de Janeiro, buscando estabelecer um diálogo com as demais pesquisas envolvidas no projeto temático, como a produção privada de habitações econômicas, as cidades novas em construção no Brasil, o desenvolvimento tecnológico e a legislação que afetava a habitação de interesse social. O relatório final dessa etapa da pesquisa constitui-se no embrião do extenso inventário apresentado nesses três volumes.

A terceira etapa da pesquisa, que ocorreu entre 2005 e 2012, foi centrada na concepção e elaboração do livro.

Os três volumes estão assim organizados: O volume 1 - "Cem anos de política pública no Brasil", traz um amplo panorama da política pública no Brasil. Está, basicamente, dividido em três partes: a primeira parte é dedicada a analisar e situar o período estudado no contexto mais geral da história econômica e social do país: os seis capítulos dessa parte cobrem a Produção rentista da habitação - 1889-1930; Origens da habitação so- 
cial - 1930-1964; Política habitacional e urbana no regime militar - 1964-1986; Décadas perdidas ou tempos de utopia e esperança? - 1986-2002; Política nacional de habitação do século XXI: em direção ao direito à moradia digna? - 20032010; e Desengavetando documentos para pensar o futuro.

A segunda parte é dedicada aos estudos dos seis principais órgãos promotores, os IAP, a Fundação da Casa Popular, o Departamento de Habitação Popular da Prefeitura do Distrito Federal (DPH) e a liga social Contra os Mocambos (LSCM) em Pernambuco. Essas análises buscam identificar as diretrizes de projeto desses órgãos, suas inovações e limitações impostas pelo quadro tecnológico, institucional e político do período.

A terceira parte do volume 1 é destinada a uma busca de síntese: "diversidade, valorização do espaço público e inserção urbana".

O volume 2, "Inventário da produção pública no Brasil entre 1930 e 1964", é integralmente dedicado à apresentação dos 322 empreendimentos projetados e construídos em todos os estados do Brasil. O inventário está estruturado em nove capítulos organizados por órgãos promotores. Contrariamente ao hábito de organizar essa vasta produção pelas 77 cidades ou 24 unidades da federação, os autores optaram por agrupá-las segundo seus realizadores. Os principais órgãos promotores montaram departamentos de arquitetura e engenharia, que se organizaram segundo diretrizes próprias, ainda que os Institutos de Pensões e Aposentadoria tivessem na personalidade do engenheiro-arquiteto Rubens Porto $^{2}$ um promotor, orientador e formulador da política habitacional, que a partir do Ministério do Trabalho, In-

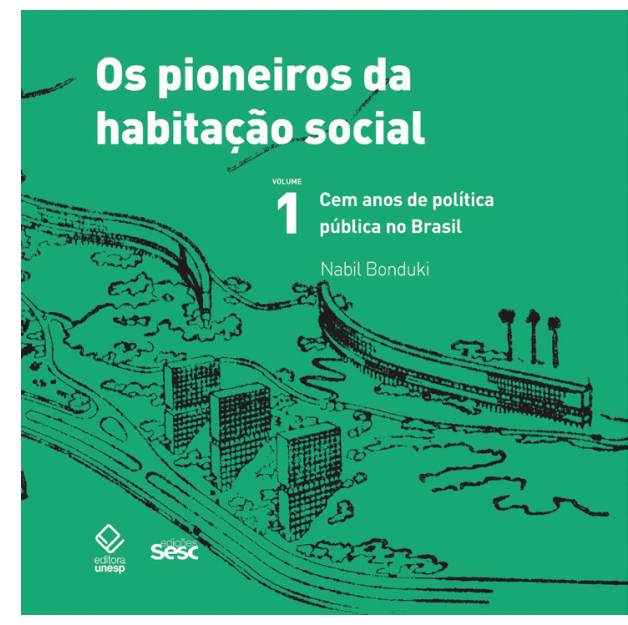

BONDUKI, N. Pioneiros da babitação social. São Paulo: Editora Unesp;

Edições Sesc, 2014. v.1: “Cem anos de política pública no Brasil.

dústria e Comércio soube induzir e formular a política levada adiante na "Era Vargas". ${ }^{3}$

No volume 1, Bonduki discute essa participação, e as propostas por ele aventadas, visando transformar a "Secretaria de Engenharia do Conselho Nacional do Trabalho, que ele chefiava em um Serviço de Engenharia e Arquitetura, subordinada diretamente ao Ministro do Trabalho, Industria e Comércio" (Almeida, 2008), buscando com isso estruturar, organizar e modernizar a capacidade técnica necessária ao projeto e execução das gigantescas obras que se previa construir. No livro publicado por ele em 1938, Porto propõe a racionalização e industrialização da construção como havia sido a experiência de Ernst May em Frankfurt, criado ao lado do Serviço de Arquitetura e Engenharia um organismo dedicado à pesquisa na área da construção, o Instituto Nacional de Tecnologia, proposta que, lamentavelmente, nunca 


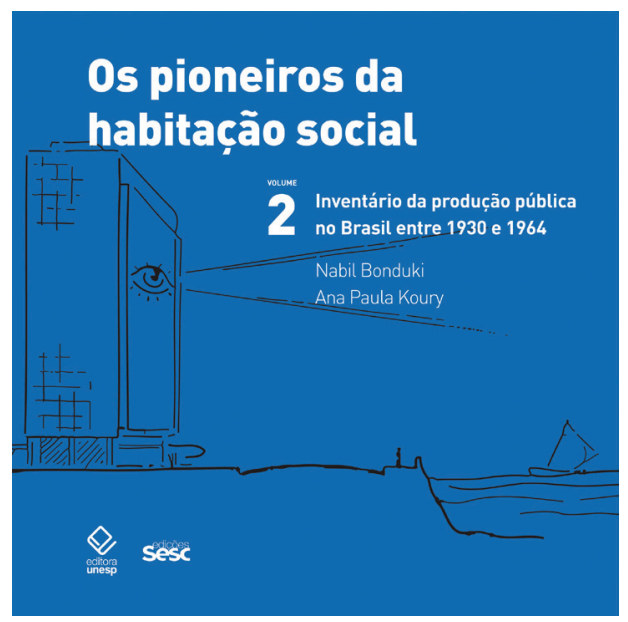

BONDUKI, N.; KOURY, A. P. Pioneiros da babitação social. São Paulo: Editora

Unesp; Edições Sesc, 2014a. v.2:

"Inventário da produção pública no Brasil entre 1930 e 1964".

foi levada adiante. Comentando essa proposta Bonduki escreveu:

A proposta do arquiteto fazia muito sentido e, se implementada, poderia ter garantido uma maior unicidade na ação habitacional dos órgãos da previdência, ampliando a capacidade de estudar, experimentar e produzir com mais eficiência e a custos mais reduzidos. No entanto, ela esbarrava no caráter corporativista da estrutura previdenciária montada por Vargas, que acabou se tornando, até 1964, um grande obstáculo a todas as tentativas de garantir um caráter mais universal e abrangente à intervenção habitacional, como ocorreu no processo de criação da FCP. (v.l, p.158)

Os nove capítulos que estruturam o volume 2 refletem a importância, o número e a qualidade das obras construídas. Assim, os três primeiros capítulos estão dedicados à produção dos IAP - Instituto de Aposentadoria e Pensões dos

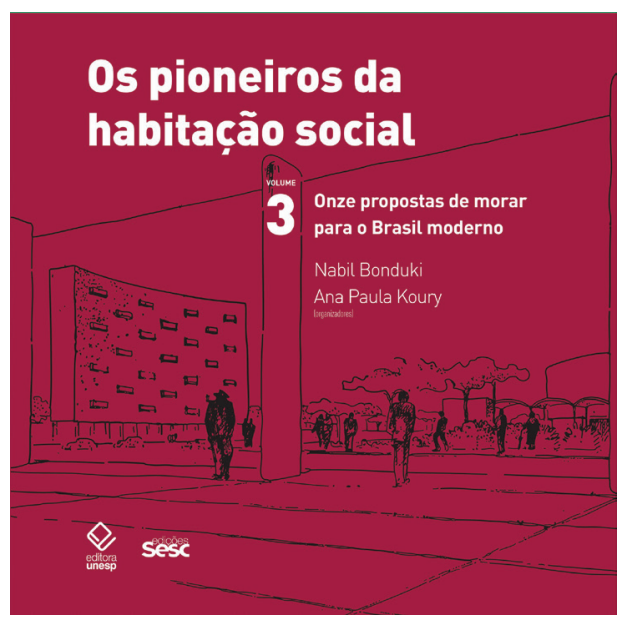

BONDUKI, N.; KOURY, A. P. Pioneiros da habitação social. São Paulo: Editora

Unesp; Edições Sesc, 2014b. v.3:

"Onze propostas de morar para o Brasil moderno".

Industriários (Iapi), com 51 empreendimentos; dos Comerciários (IAPC), com 57 empreendimentos; e dos Bancários (IAPB), com 48 empreendimentos. O capítulo 4 está dedicado à produção do Instituto de Previdência e Assistência dos Servidores do Estado (Ipase), com 26 obras. Os demais capítulos agrupam a produção de órgãos cujas realizações são menos expressivas do ponto de vista quantitativo ou qualitativo. O capítulo 5 traz a produção do IAPTEC, IAPM e do Iape; o capítulo 6 da CAP, CAPFESP e IAPFESP; o capítulo 7, da Fundação da Casa Popular (FCP) com 29 empreendimentos em todo o Brasil; o capítulo 8 compila a obra de órgãos regionais; e o capítulo 9 traz as áreas residenciais de algumas cidades novas promovidas pelo governo federal ou por empresas estatais: Volta Redonda, Cidade dos Motores, Ipatinga e Brasília até 1964.

O trabalho se tornaria extenso em demasia se fossem analisadas as vilas e cida- 
des novas construídas junto as barragens ou minas, o que indica que a pesquisa ainda não está completa, abrindo portas e sugestões de novos trabalhos, dissertações e teses. Essa é mais uma qualidade do trabalho ora publicado.

$\mathrm{O}$ volume 3 apresenta, analisa e discute onze conjuntos residenciais realizados entre 1930 e 1964, considerados de particular interesse, seja do ponto de vista da qualidade arquitetônica, inserção urbana, seja do ponto de vista da diversidade tipológica e construtiva. A escolha desses onze projetos foi amplamente discutida pelo grupo de alunos de pós-graduação que estabeleceu critérios comuns para a abordagem dos conjuntos, dentre os quais o contexto urbano em que foram implantados, a escolha das tipologias predominantes, a identificação das influências e dos autores dos projetos, bem como a construção, a gestão e o uso social dos conjuntos. Nesse levantamento mais cuidadoso foi importante fotografar novamente cada conjunto, mostrando a situação atual e identificando as partes eventualmente não construídas. Finalmente, o autor revisou todas as pesquisas de modo a uniformizar os textos e garantir uma estrutura consistente. Pelo interesse que apresentam os onze capítulos tratam dos seguintes conjuntos habitacionais:

- O capítulo "Realengo: reprodutibilidade e singularidade" examina o primeiro grande conjunto habitacional do Iapi, projeto do arquiteto Carlos Frederico Ferreira, construído entre 1938 e 1943, junto à estação do mesmo nome no Rio de Janeiro. Foi premiado no IV Congresso Pan-Americano de Arquitetos, que ocorreu em Montevidéu em 1940.

- O capítulo "Várzea do Carmo: o racionalismo radical de Attilio Correa
Lima" examina a proposta, que talvez seja a de maior complexidade e vanguarda no período tratado no livro. Localizado junto ao Parque D. Pedro I em São Paulo, além de habitações de interesse social, o conjunto previa usos mais rentáveis como habitação para setores médios, comércio, serviços, escolas, creches, de modo a garantir o equilíbrio econômico que o Iapi buscava. Ficou inacabado com a morte do arquiteto em 1943, pois só foram construídos 22 blocos de quatro pavimentos com 552 unidades.

- O capítulo "Lagoinha: espaço público de qualidade sacrificando a unidade habitacional" examina o Bairro Indus-triário em Belo Horizonte. Trata-se de um dos mais originais empreendimentos do Iapi em parceria com a prefeitura e uma entidade privada denominada Companhia Auxiliadora de Serviços Administrativos (Cada). No início dos anos 1940, quando o conjunto foi construído, era prefeito de Belo Horizonte o futuro presidente Juscelino Kubitschek de Oliveira, que promoveu a parceria, que não mais se renovou.

- O capítulo “Passo d'Areia: habitação social e extensão urbana”, em Porto Alegre, aborda o maior conjunto habitacional em número de unidades. O estudo urbanístico, implantado no limite da área urbanizada, projeto do engenheiro José Otacílio de Saboya Ribeiro, mostra como as cidades brasileiras poderiam crescer de forma ordenada. O plano urbanístico do conjunto é de engenheiro Marcos Kruter e o projeto das unidades, bem como a direção das obras, é do engenheiro Edmundo Gardolinski, 1942.

- O capítulo "Olaria: racionalidade construtiva e urbanismo monumental nas cidades - jardins dos comerciários" 
analisa o conjunto habitacional implantado pelo IAPC no bairro Olaria no Rio de Janeiro, cuja concepção é do engenheiro Ulysses Hellmeister, 1938. Ainda que a moradia fosse individual, a tipologia era baseada em unidades sobrepostas em renques escalonados de modo a evitar, no entender do autor do projeto, os prejuízos morais e higiênicos das moradias coletivas. A solução gerava economia de custos e aumento das áreas verdes.

- O capítulo "Edifício Japurá: uma unidade de habitação no centro da cidade de São Paulo" analisa uma experiência proposta pelo arquiteto Eduardo Kneese de Mello, 1942, para o Iapi. Trata-se de um edifício de grande altura para a época, de uso misto, suspenso em pilotis, teto jardim e unidades duplex, que possibilitou um bom aproveitamento de um terreno de difícil ocupação.

- O capítulo "Pedregulho: habitação social como serviço público" revisita o principal empreendimento do Departamento de Habitação Popular (DHP) da prefeitura do Distrito Federal. O conjunto, talvez o mais publicado e divulgado no Brasil e no exterior, é fruto do trabalho da engenheira Carmen Portinho, como diretora do DHP, e do arquiteto Affonso Eduardo Reidy. O projeto é de 1946, e sempre foi tratado como uma obra de exceção no contexto da arquitetura do período considerado.

- O capítulo "Penha: de um projeto autoral a uma proposta funcional da equipe do Iapi" examina um dos conjuntos em que se observa a passagem, que nos anos 1940, viveu o Iapi, quando formou um quadro de profissionais selecionados em concurso público e que impuseram um maior rigor e pragmatismo na produção do órgão. O primeiro projeto dos irmãos MMM Roberto de 1939 foi definido como "solução fantasiosa e inviável", abandonada e substituída por outra proposta racional e mais econômica.

- O capítulo "Deodoro: urbanismo moderno e concepção convencional", realizado pelo arquiteto Flavio Marinho Rego o Conjunto Residencial Presidente Getulio Vargas, data de 1952 e, possivelmente, seja a maior realização da FCP. Com 1.314 unidades, foi fortemente influenciado pelo arquiteto Affonso Eduardo Reidy, que naquele momento integrava o Conselho Central da FCP. O projeto tem o mérito de combinar as diretrizes urbanísticas de Reidy com a escassez de recursos do órgão, numa obra de grande porte e engenhosidade.

- O capítulo "Casa Bancária: um ambiente cristão e moderno para integração das mulheres no mercado de trabalho", do IAPB, é projeto do arquiteto Carlos Leão e data de 1956. Era voltado para funcionárias bancárias solteiras, agregando, além de dormitórios, espaços coletivos que complementam sua função.

- O capítulo "Paquetá: novo modo de morar com respeito à escala local" é um projeto do Departamento de $\mathrm{Ha}$ bitação Popular do Distrito Federal (DHP). O projeto de 1952 é do arquiteto Francisco Bolonha. Sob a direção segura da engenheira Carmen Portinho, o DHP colocou em prática a ideia da habitação como um elemento estruturador da família trabalhadora. Na sua singele$\mathrm{za}$, formado por dois blocos em L com 27 casas e o escritório do serviço social, Paquetá é um dos mais belos exemplos da produção habitacional do período estudado.

Mas o grande interesse que esses três volumes trazem para a historiografia da arquitetura brasileira foi muito bem cap- 
Conjunto Residencial Operário, Iapi. Bairro do Realengo, Rio de Janeiro, RJ. Projeto de Carlos Frederico Ferreira, 1938.

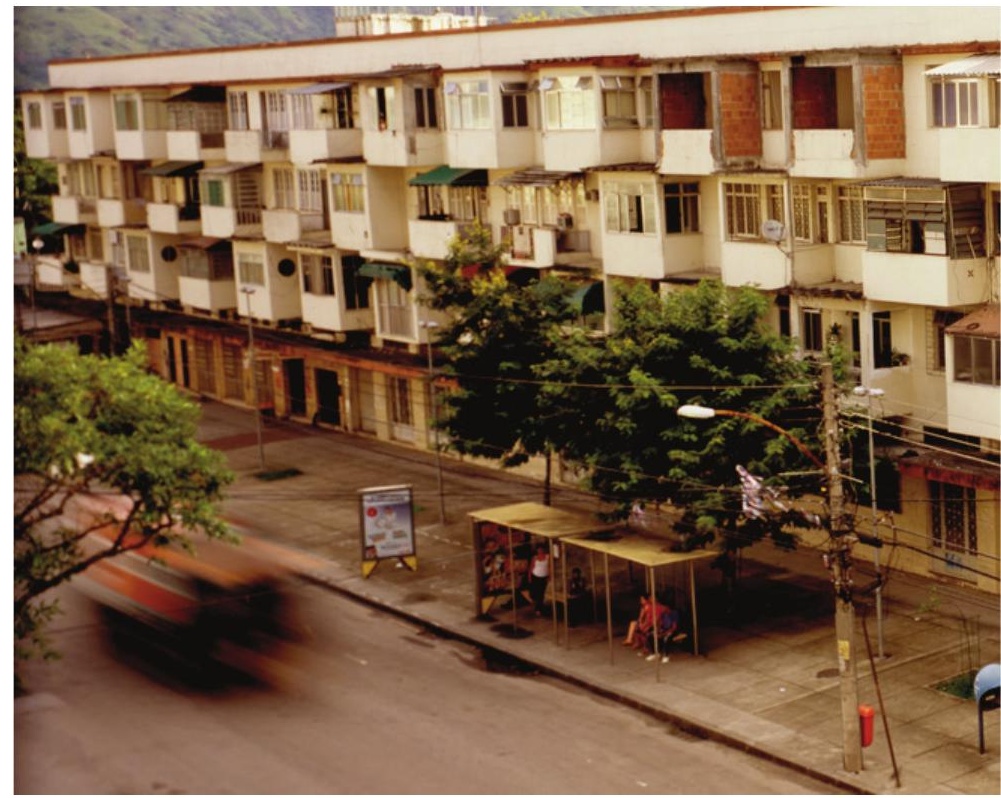

Conjunto Residencial da Penba, Iapi Bairro da Penha, Rio de Janeiro, RJ. Projeto: MMM Roberto, 1939 (Abandonado). Divisão de Engenharia do Iapi, 1947.

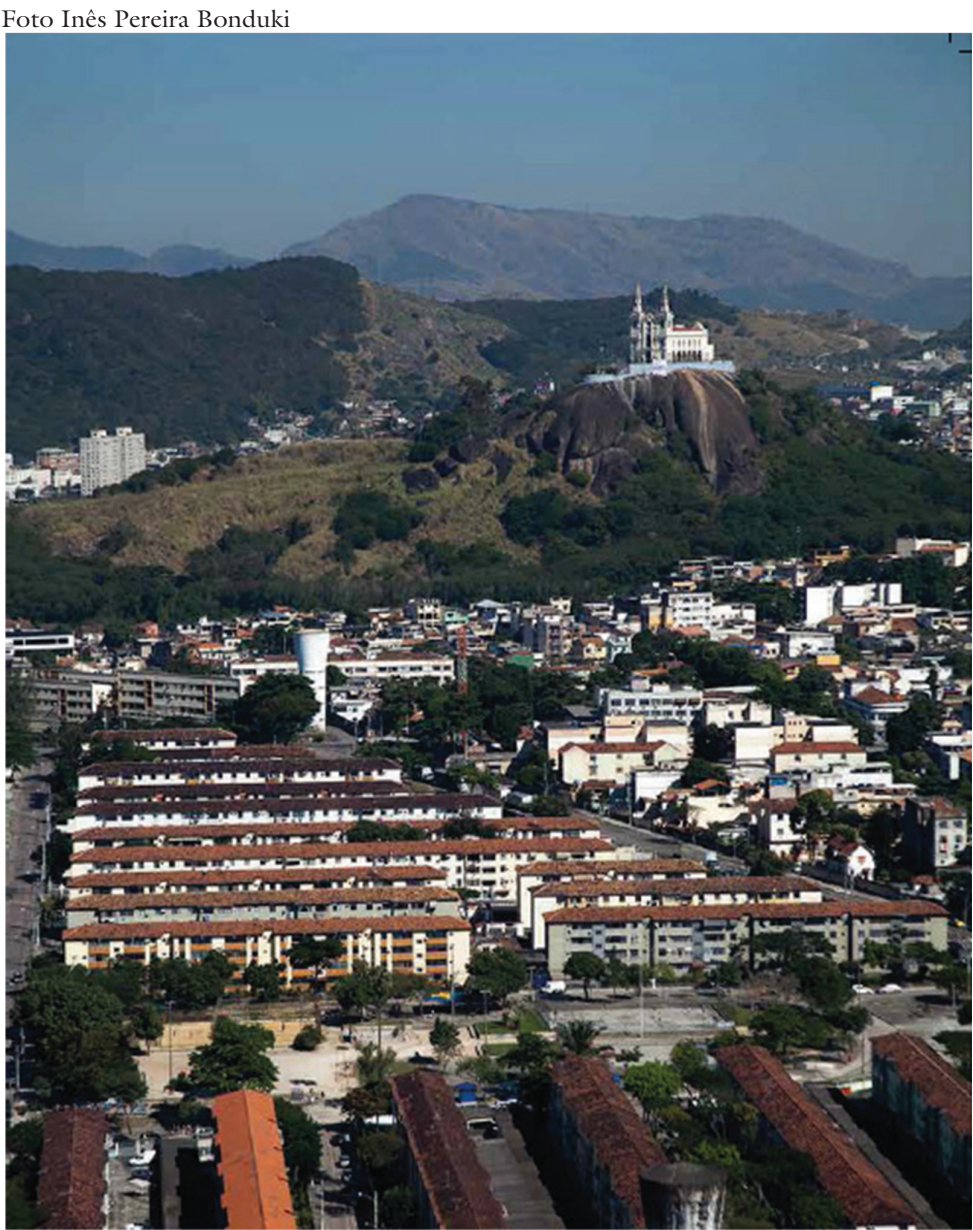


tado pelo arquiteto Carlos Ferreira Martins, que na apresentação do volume 2 escreveu:

... esse mito tem, provavelmente, sua origem no conjunto de debates que em meados dos anos 1950 marcou o fim do consenso internacional sobre os rumos do desenvolvimento da arquitetura moderna no Brasil e, mais especificamente, na feroz crítica de Max Bill. Desde então cristalizou-se a visão de uma arquitetura descomprometida com os programas sociais e a leitura da obra exemplar de Affonso Eduardo Reidy como a exceção a confirmar a regra. É notável que o trabalho de Yves Bruand, "Arquitetura Contemporânea no Brasil" (1981), seguramente a mais abrangente narrativa de conjunto da arquitetura brasileira do século XX, não dedique um capítulo específico ao programa habitacional.

Efetivamente causa profunda estranheza o silêncio da crítica arquitetônica brasileira mais recente a esse extraordinário conjunto de obras, apresentadas de forma tão clara e metódica pelos três volumes coordenados e regidos por $\mathrm{Na}$ bil Bonduki e Ana Paula Koury. Mas não foi sempre assim, pois desde os anos 1940 essas obras mereceram atenção e considerável interesse. O primeiro livro a divulgar a nascente arquitetura moderna brasileira foi o catálogo da exposição Brazil Builds - Architecture New and Old 1652-1942, que se realizou no Museu de Arte Moderna de Nova York (Moma) em 1943. O arquiteto Philip Goodwin, que acompanhado pelo fotógrafo G. E Kidder Smith esteve no Brasil por mais de seis meses, escreveu:

Há um grande número de projetos, muitos dos quais em construção, de grandes conjuntos habitacionais de baixo custo, como os que foram construídos na Europa e mais recentemente nos Estados Unidos. Attilio Correa Lima projetou um amplo conjunto para um bairro industrial de São Paulo. ${ }^{4}$ Inclui um grande número de prédios de apartamentos, escritórios, e edifícios comunitários. Realengo é uma interessante experiência de habitação coletiva compreendendo tanto apartamentos como casas isoladas. (p.96)

O livro dedica quatro páginas ao conjunto do Realengo (1939-1943). Comentando a solução para a circulação externa dos blocos de quatro pavimentos, para as quais se abrem apenas as janelas altas das cozinhas e dos banheiros, o autor escreveu tratar-se de uma "solução ideal para o clima do Brasil, pois confere a cada apartamento uma completa ventilação cruzada" (p.128).

Depois dessa exposição foram frequentes os números monográficos das revistas estrangeiras sobre a arquitetura moderna brasileira. The Architectural Forum (nov. 1947) publicou cinco projetos: Várzea do Carmo, Santo Antonio e Cidade Jardim (não construído) todos em São Paulo; Realengo no Rio de Janeiro e os primeiros desenhos para o conjunto de Pedregulho. Na revista dirigida por André Bloc, L'Architecture D'Aujourd'hui (ago. 1952), foram publicados dois projetos de cunho social do arquiteto Eduardo Knees de Mello: Cidade Jardim e Japurá em São Paulo. O conjunto do IAPC na Avenida Cidade Jardim, ainda que não estivesse construído, mereceu um destaque no livro de Alberto Sartoris (1954, p.252ss) dedicado à nova arquitetura na América Latina. Em 1956 finalmente foi publicado o magnífico livro do arquiteto Henrique 
Mindlin, ${ }^{5}$ com prefácio de Sigfried Giedion, que pretendia fazer um balanço completo da arquitetura moderna brasileira. Nessa extensa relação de obras aparece apenas o conjunto de Vila Guiomar em Santo André, para o Iapi, projeto do arquiteto Carlos Frederico Ferreira. Construído em 1949, tinha 594 apartamentos em blocos de três pavimentos sobre pilotis e casas geminadas. Do mesmo arquiteto, que era o diretor do Departamento de Engenharia do Iapi, é o projeto da bela escola para 1.200 alunos, igualmente publicada e premiada na $1^{a}$ Bienal Internacional de Arquitetura de São Paulo.

A partir dessa data, com o início da construção de Brasília, o interesse dos críticos desloca-se para uma nova capital, onde os IAP realizarão suas últimas obras antes de serem extintos em $1964 .^{6}$ Depois dessa data, mesmo livros, que pretendiam cobrir todo o conjunto da arte e da arquitetura no Brasil, nada mencionam sobre esse extenso volume de obras, como é o caso da História geral da arte no Brasil, cuja coordenação foi do crítico Walter Zanini (1983), e para o qual Carlos A. C. Lemos escreveu o capítulo sobre arquitetura contemporânea. O mesmo se pode dizer da antologia organizada por Alberto Xavier (1987), Depoimento de uma geração: Arquitetura moderna brasileira. ${ }^{7}$ Não é o caso de repetir os comentários acima sobre o livro de Yves Bruand (1991), que apenas cita de forma elogiosa o conjunto de Pedregulho do arquiteto Affonso Eduardo Reidy.

Na literatura mais recente, como no livro de Hugo Segawa (1998), Arquitetura no Brasil (1900-1990), o tema é tratado com propriedade. Veja-se o capítulo "Habitar moderno", que mostra de forma muito concisa, mas correta, algumas obras do período considerado. Porém, essa é uma exceção, pois o tema volta a desaparecer dos tratados, que se debruçam sobre a arquitetura após 1950 (Junqueira Bastos; Zein, 2010).

Em conclusão, fica evidente que a crítica e os historiadores da arquitetura deverão rever de forma radical o entendimento da arquitetura brasileira no século XX. Os três volumes coordenados e redigidos por Nabil Bonduki e Ana Paula Koury são a testemunha documental, rigorosa e rica de um conjunto de obras que situam o movimento moderno no Brasil muito além das fantasias formais a que aparentemente estava condenada a arquitetura brasileira.

São Paulo, fevereiro 2015.

\section{Notas}

1 Dentre os mais interessantes volumes publicados destacam-se: Devecchi (2014); $\mathrm{a}+\mathrm{t}$ research group, "10 Histórias sobre vivienda colectiva. Análisis gráfico de diez obras esenciales", Vitória-Gasteiz: a + t architecture publishers, España, 2013.

$2 \mathrm{O}$ engenheiro arquiteto Rubens Porto era assistente técnico do ministro do trabalho e engenheiro do Serviço de Engenharia do Conselho Nacional do Trabalho. Fazia parte de um grupo de reformadores sociais católicos, que defendiam uma maior intervenção do Estado na questão da habitação. Com vínculos na Organização Mundial do Trabalho em Genebra, Porto, através da imprensa e de publicações do Ministério, defendia a necessidade de dar estabilidade à família do trabalhador urbano através da construção de conjuntos pela ação estatal. Publicou em 1938 um livro, O problema das Casas Operárias e os Institutos e Caixas de Aposentadoria e Pensões, no qual organiza e 
detalha suas recomendações para a construção dos grandes conjuntos habitacionais modernos.

3 Veja-se o discurso pronunciado por Getulio Vargas em 10 de novembro de 1938 , por ocasião do primeiro aniversário da Constituição do Estado Novo, em A Nova Politica do Brasil, v.VI: "Realizações do Estado Novo, $1^{\circ}$ de agosto de 1938 a 7 de setembro de 1939", Rio de Janeiro, p.99 e 100. Ver também Bastos e Fonseca (2012).

4 Philip Goodwin deve estar se referindo ao conjunto da Várzea do Carmo, projetado para o Iapi e naquele momento em obras. O arquiteto Attilio C. Lima projetou ainda um outro conjunto habitacional em São Paulo, na área de Heliópolis, para dezesseis mil habitantes, cujos dados nunca foram localizados após o acidente aéreo, que vitimou o arquiteto em 1943.

5 Henrique E. Mindlin, L'architecture moderne au Brésil, 1956. Foi publicado simultaneamente por várias editoras $\mathrm{em}$ inglês, francês e alemão.

6 Toda essa narrativa consta em Bruna (2010, p.160).

7 Cf. Xavier (1987). Nesse livro, ver algumas referências esparsas como as de Vilanova Artigos (1952) (p.141); Maurício Vinha de Queiroz (1962) (p.166) e Affonso Eduardo Reidy (1961) (p.184).

\section{Referências}

ALMEIDA, C. C. O. de. O engenheiro arquiteto Rubens Porto e os Institutos e Caixa de Aposentadoria e Pensões (IAPs/ CAPs); contribuições para a formulação de uma política pública habitacional no Brasil na década de 1930. Risco, São Carlos, n.8, 2008.

BASTOS, P. . Z.; FONSECA, P. C. D. (Org.) A Era Vargas - Desenvolvimento, economia e sociedade. São Paulo: Editora Unesp, 2012.
BONDUKI, N. G. Origens da habitação social no Brasil: o caso de São Paulo. 1994. Tese $($ Doutorado) $=$ Faculdade de Arquitetura e Urbanismo, Universidade de São Paulo. São Paulo. 1994.

BRAND, Y. Arquitetura contemporânea no Brasil. Trad. Ana M. Goldberger. São Paulo: Perspectiva, 1991.

BRUNA, P. Os primeiros arquitetos modernos. Habitação Social no Brasil 19301950. São Paulo: Edusp, 2010.

DEVECCHI, A. M. Reformar não é construir; A reabilitação de edifícios verticais - novas formas de morar em São Paulo no século XXI. São Paulo: Senac, 2014.

FARAH, M. F. dos S. Estado, Previdência Social e Habitação. 1983. Dissertação (Mestrado) - Faculdade de Filosofia, Letras e Ciências Humanas, Universidade de São Paulo. São Paulo, 1983.

JUNQUEIRA BASTOS, M. A.; ZEIN, R. V. Brasil: arquiteturas após 1950. São Paulo: Perspectiva, 2010.

SARTORIS, A. Encyclopédie de l'Architecture Nouvelle. s. 1.: s. n., 1954. v.3 "Ordre et Climat Américains".

SEGAWA, H. Arquiteturas no Brasil 1900-1990. São Paulo: Edusp, 1998.

XAVIER, A. (Org.) Depoimento de uma geração. Arquitetura moderna brasileira. São Paulo: Associção Brasileira de Ensino de Arquitetura, Fundação Vilanova Artigas, Pini, 1987.

ZANINI, W. (Org.) História geral da arte no Brasil. São Paulo: Instituto Walter Moreira Sales, 1983. 2v.

Paulo Bruna é professor titular do Departamento de História da Arquitetura da FAU-USP. @-pb@paulo-bruna.com.br

I Faculdade de Arquitetura e Urbanismo, Universidade de São Paulo, São Paulo/SP, Brasil. 